\title{
Bronchoscopy in diagnosis of haemoptysis
}

The authors declare no financial disclosure

\section{Dear Editor,}

With great interest, we read the article by Torbiarczyk et al. on bronchoscopy in diagnosis of haemoptysis (Adv Respir Med. 2018; 86: 13-16) [1]. We are also very interested in this procedure for patients with active hemoptysis [2]. We would like to ask three points. First, the authors described that patients with active bleeding did not differ significantly according to age. With regard this analysis, we do appreciate hearing from the authors whether the cutoff age was 59 or not. If so, why the authors selected this age as the cutoff age? Since the median age of the patients studied was this age, did the authors set the age of cutoff to 59 years? Second, please let us know the definition of "no visible abnormalities". The authors reported that they detected that patients with no visible abnormalities were significantly younger. Please explain how to understand the meaning of this result. Does that mean that we should consider the association with diseases with high frequency of blood sputum in younger patients? Third, even if bleeding lesions are not confirmed directly, we do evaluate that information on which lober or segmental bronchus is related to bleeding and the useful information for performing bronchography and bronchial artery embolization are important. Please let us know how the authors think about.

\section{Conflict of interest}

The authors declare no conflict of interest.

\section{References:}

1. Torbiarczyk JM, Sobczak PA, Torbiarczyk KK, et al. Is bronchoscopy always justified in diagnosis of haemoptysis? Adv Respir Med. 2018; 86(1): 13-16, doi: 10.5603/ARM.2018.0004, indexed in Pubmed: 29490417.

2. Watanabe H, Katayama K, Satoh H. Timely bronchoscopic examination for a patient with hemoptysis. Tuberk Toraks. 2016; 64(3): 258-259, indexed in Pubmed: 28393734. 